\title{
Fractura compleja de escápula
}

\author{
Complex scapula fracture
}

\author{
Carlos Iván Andrade Aguilar,* Edgar Turrubiates Lucero, * \\ Bernardo Andrade Aguilar, ${ }^{\ddagger}$ Luis Gerardo Domínguez Carrillo ${ }^{\S}$
}

\section{Resumen}

Introducción: Las fracturas de la escápula representan el $0.7 \%$ de todas las fracturas. En la mayoría de los casos, un traumatismo de alta energía está involucrado, por lo que son necesarias la radiografía y la tomografía computarizada de tórax para descartar lesiones ocultas. Caso clínico: Hombre de 37 años, jornalero de ocupación. Ingresó a Urgencias con un politraumatismo que se originó al ser impactado en su bicicleta por un automóvil, recibiendo impacto de alta energía cinética. Se le diagnosticó fractura compleja de escápula, sin problemas concomitantes ni asociados. Se efectuó reducción abierta y fijación con osteosíntesis, con buena evolución postquirúrgica y de rehabilitación, alcanzando 89 en escala de DASH a su alta. Conclusiones: Ante cualquier fractura de escápula, se debe investigar si existen lesiones ocultas.

Palabras clave: Fractura de escápula, fractura compleja de escápula, tratamiento de fractura de escápula.

\section{CASO CLÍNICO}

Se trata de un hombre de 37 años, jornalero de ocupación. Ingresó a Urgencias con politraumatismo que se originó al ser impactado en su bicicleta por un automóvil, siendo un impacto de alta energía cinética. A la exploración física, se evidenció Glasgow de 14 puntos; el cráneo presentaba heridas contusas y escoriaciones en cara; hemitórax izquierdo con escoriaciones, discreta disminución en

* Ortopedista. División de Cirugía del Hospital Ángeles León.

* Cirujano General. División de Cirugía del Hospital Ángeles León.

$\S$ Especialista en Medicina de Rehabilitación. Profesor de la Facultad de Medicina de León, Universidad de Guanajuato.

León, Guanajuato, México.

Correspondencia:

Dr. Carlos Iván Andrade Aguilar

Correo electrónico: cuatotte@yahoo.com

Aceptado: 30-08-2019.

www.medigraphic.com/actamedica

\section{Abstract}

Introduction: Scapula fractures represent $0.7 \%$ of all fractures. In most cases a high-energy trauma is involved, chest radiograph and computed tomography are important to rule out hidden lesions. Case report: A 37-year-old male laborer, with polytrauma caused by impact of his bicycle by car, receiving high kinetic energy impact, diagnosing a complex scapula fracture, with no concomitant or associated problems. Open reduction and fixation with osteosynthesis were performed, with good postsurgical and rehabilitation evolution reaching 89 in DASH scale at discharge. Conclusions: In case of a scapula fracture others hidden lesions should be investigated.

Keywords: Scapula fracture, scapula fracture treatment, scapula multifragmented fracture.

ampliación y amplexación por dolor; el campo pulmonar izquierdo estaba con murmullo vesicular disminuido, sin modificaciones en percusión, ruidos cardiacos rítmicos y sin fenómenos agregados; equimosis y aumento de volumen en región escapular y hombro izquierdo, con imposibilidad para movimientos activos del mismo. La sensibilidad de miembro torácico izquierdo, reflejos osteotendinosos y llenado capilar fueron normales, al igual que en la extremidad torácica contralateral.

El abdomen se encontraba normal, así como las extremidades pélvicas. Se efectuaron estudios tomográficos de cráneo, radiografías de tórax y tomografía de cintura escapular; esta última mostró una fractura compleja de escápula (Figuras 1 y 2). Después de ser valorado por los departamentos de Neurocirugía y Cirugía general, se descartaron lesiones intracraneales y abdominales. De esta manera, previo aseo y debridación de heridas contusas de cráneo, se le realizó la sutura de estas lesiones. Posteriormente, ingresó a cirugía de escápula con reducción abierta y osteosíntesis con placas de reconstrucción (Figura 3), cuyos resultados fueron adecuados (Figura 4); la contusión pulmonar de hemitórax izquierdo se le manejó médicamente. 
La evolución del paciente fue satisfactoria; éste recibió rehabilitación por dos meses, obteniendo calificación de $89 \mathrm{al} \mathrm{momento} \mathrm{de} \mathrm{su} \mathrm{alta.} \mathrm{En} \mathrm{el} \mathrm{seguimiento} \mathrm{a} \mathrm{seis} \mathrm{meses}$ de la cirugía obtuvo una calificación de 92 en la escala de DASH (Disabilities of the Arm, Shoulder and Hand).

\section{DISCUSIÓN}

Las fracturas de la escápula representan el $0.7 \%$ de todas las fracturas y del 3 al 5\% de las fracturas de la cintura escapular. ${ }^{1}$ Este tipo de fractura es delicada, ya que 18 músculos se originan o cruzan la escápula y la articulación glenohumeral, y su incorrecta alineación o mala unión posterior a una fractura implica problemas para realizar la función adecuada de la extremidad torácica. Dado que en la mayoría de los casos de fractura de escápula está involucrado un traumatismo de alta energía, la búsqueda de lesiones asociadas es imprescindible, puesto que se han reportado lesiones concomitantes en el $31.5 \%$ en la cabeza; en el $36.8 \%$ en tórax, incluyendo un $3.95 \%$ en grandes vasos. ${ }^{2}$ El estudio de Baldwin y su equipo ${ }^{3}$ donde revisaron 9,400 fracturas de escápula concluyó que en el $52.9 \%$ se encontró fractura concomitante de costillas; en el $29.1 \%$, fracturas de columna vertebral; en el $47.1 \%$, lesiones pulmonares, y en el $13 \%$, lesiones asociadas con lesión del plexo braquial, con alto riesgo de lesión de los nervios supraescapular y circunflejo. Esto evidencia que los estudios radiológicos sólo de la fractura de escápula
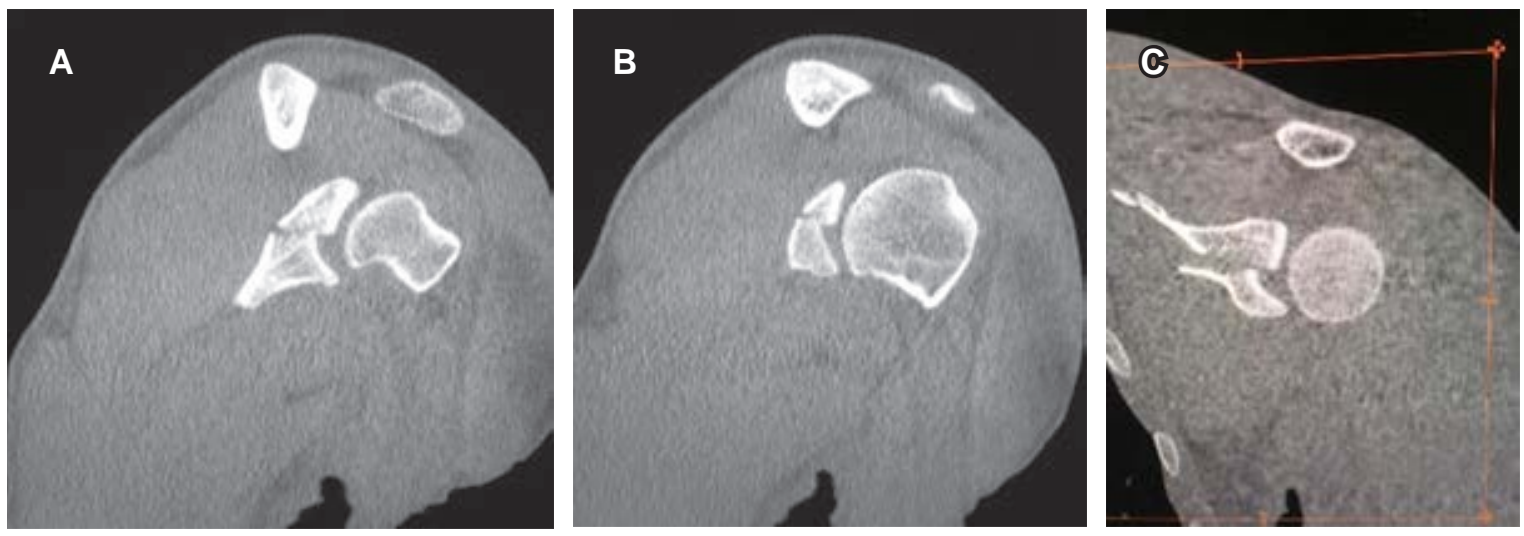

Figura 1: Imágenes tomográficas de la articulación glenohumeral izquierda: (A y B) en plano sagital y (C) en abducción, las cuales muestran una fractura transversa intraarticular de glenoides tipo II A de acuerdo con la clasificación de Ideberg y tipo 14 F1.3 de la clasificación Orthopaedic Trauma Association.
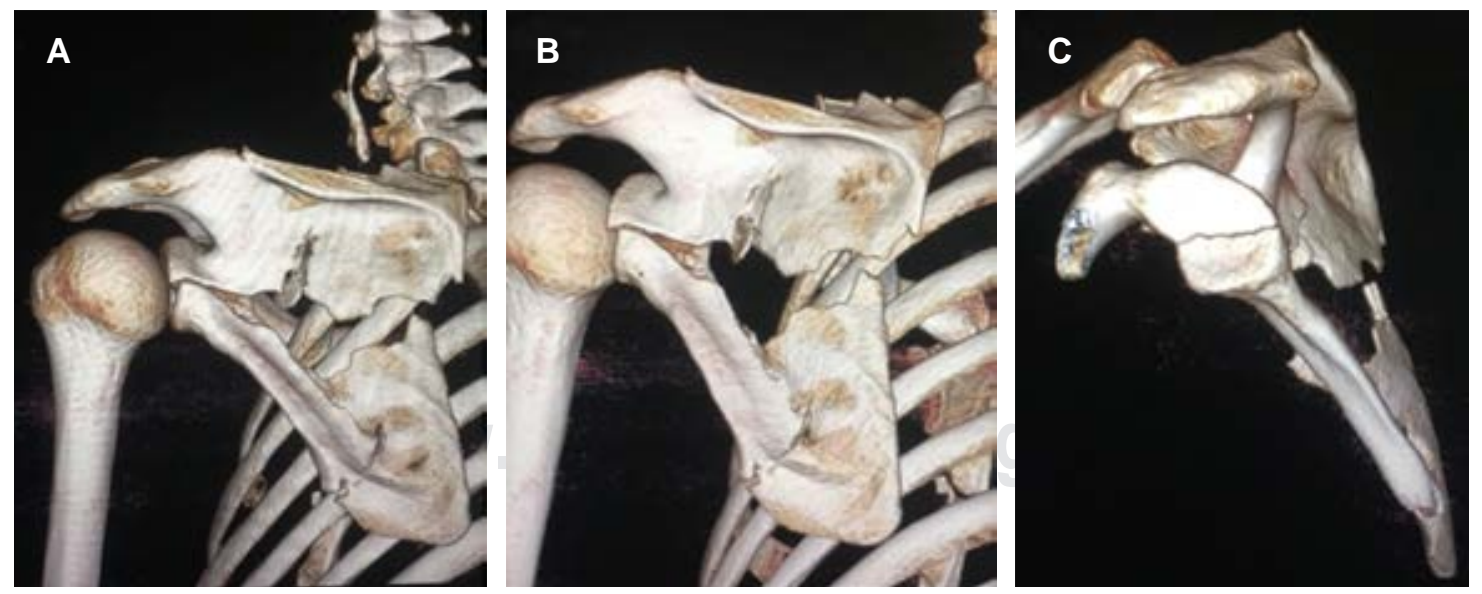

Figura 2: Imágenes de reconstrucción tomográficas en 3D de fractura multifragmentaria de escápula, que corresponden al tipo 14 F1.3 desde el punto de vista glenoideo y 14 B3.2 del cuerpo de la escápula de la clasificación de la Orthopaedic Trauma Association. (A) Vista de cara posterior en el plano coronal; (B) acercamiento de escápula en plano coronal; (C) vista en el plano sagital mostrando lesión intraarticular de tipo transverso de la glenoides izquierda. 
implican tres proyecciones básicas ${ }^{4}$ (proyección anteroposterior verdadera, axial del hombro y lateral de escápula), siendo necesarias la radiografía tele de tórax y tomografía computarizada de tórax para descartar lesiones ocultas.

En general, el manejo de las fracturas de escápula es conservador, como lo demuestra el estudio de Dimitroulias y colaboradores, ${ }^{5}$ el cual indica que los resultados con tratamiento conservador son satisfactorios en la escala de DASH, ${ }^{6}$ reservando el manejo quirúrgico para aquellas fracturas desplazadas más de $20 \mathrm{~mm}$ y con angulaciones mayores de $45^{\circ}$ y para fracturas intraarticulares de la glenoides con desplazamientos mayores de $4 \mathrm{~mm}$ y/o más de $20 \%$ de afección de la superficie glenoidea, ${ }^{5}$ la cual puede ser manejada por artroscopia. ${ }^{7}$ En nuestro caso, el motivo de decisión quirúrgica fue un desplazamiento mayor de $20 \mathrm{~mm}$ de los fragmentos del cuerpo de la escápula, pero principalmente la afectación de la superficie articular de la glenoides.

Las dificultades técnicas en este caso implicaron una amplia disección para colocar el material de osteosíntesis, por último, como se anota en la presentación del caso, los resultados fueron excelentes en la escala de DASH, cuya calificación final fue de 92 .

Dado que este tipo de fracturas no son frecuentes, las indicaciones quirúrgicas no son precisas; sin embargo, las

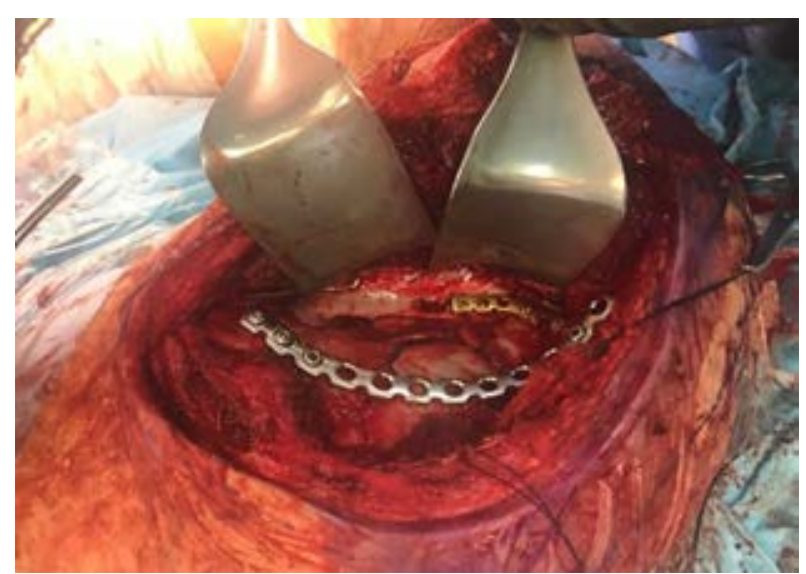

Figura 3: Imagen del campo quirúrgico con reducción abierta de fractura de escápula izquierda y material de osteosíntesis.
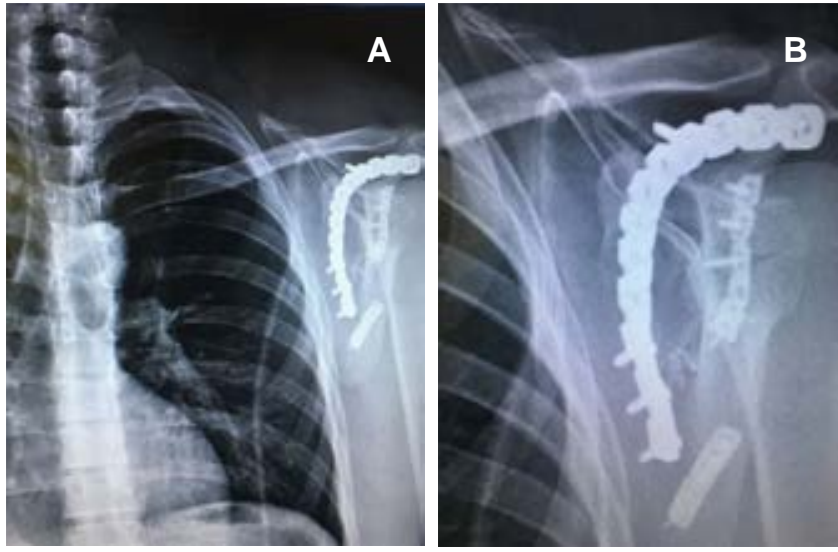

Figura 4: Radiografías (A) postoperatorias de la fractura de escápula, la cual se manejó con osteosíntesis. (B) Acercamiento.

metas de la cirugía son disminuir el riesgo de artrosis, dolor, rigidez residual y obtener un miembro superior funcional con apoyo de la rehabilitación.

\section{REFERENCIAS}

1. Cole AP, Freeman G, Dubin RJ. Scapula fractures. Curr Rev Musculoskelet Med. 2013; 6: 79-87.

2. Gottschalk HP, Browne RH, Starr AJ. Shoulder girdle: patterns of trauma and associated injuries. J Orthop Trauma. 2011; 25: 266-271.

3. Baldwin KD, Ohman-Strickland P, Mehta S, Hume E. Scapula fractures: a marker for concomitant injury? A retrospective review of data in the national trauma database. J Trauma. 2008; 65: 430435.

4. Anavian J, Conflitti JM, Khanna G et al. A reliable radiographic measurement technique for extra-articular scapular fractures. Clin Orthop Relat Res. 2011; 469: 3371-3378.

5. Dimitroulias A, Molinero KG, Krenk DE, Muffly MT, Altman DT, Altman GT. Outcomes of nonoperatively treated displaced scapular body fractures. Clin Orthop Relat Res. 2011; 469: 14591465.

6. Hervás MT, Navarro CJ, Peiro S, Martínez TI. Versión española del cuestionario DASH. Adaptación transcultural, fiabilidad, validez y sensibilidad a los cambios. Med Clin. 2006; 127: 441-447.

7. Yallapragada R, Patel K, Davuluri P, Sloan A, Marynissen H. Arthroscopy-assisted percutaneous fixation of glenoid fossa fracture. Int J Should Surg. 2007; 1: 96-98.

8. Jones CB, Sietsema DL. Analysis of operative versus nonoperative treatment of displaced scapular fractures. Clin Orthop Relat Res. 2011; 469: 3379-3389. 